JPIF

37,6

Received 30 June 2019 Accepted 19 July 2019

\section{Blockchain technology in commercial real estate transactions}

\author{
Hugo Pieter Wouda \\ Department of Architecture Building and Planning, \\ Eindhoven University of Technology, Eindhoven, The Netherlands and \\ Deloitte, Amsterdam, The Netherlands, and \\ Raymond Opdenakker \\ Department of Industrial Engineering and Innovation Sciences, \\ Eindhoven University of Technology, Eindhoven, The Netherlands
}

\begin{abstract}
Purpose - The transaction process of an office building is known to be time consuming and inefficient, in part due to the lack of market transparency. The purpose of this paper is to focus on the development of a blockchain application that can improve the transaction process of office buildings in the Netherlands.

Design/methodology/approach - Conducting design science research, the current transaction process of an office building and status quo of blockchain technology in real estate is investigated. Subsequently, multiple parties are interviewed to define major pain points within the process. The interview findings are used to design a blockchain solution which overcomes the aforementioned pain points. After designing, the interviewees are asked again to pragmatically validate the proposed model.

Findings - One of the major pain points identified concerning the transaction process of an office building is that it is difficult to define the characteristics of a property, due to lack of data structure and quality. The proposed application improves the way specific assets are understood by structuring physical and contractual information in one place and guarantees the quality of the data by using the blockchain mechanisms.

Practical implications - A blockchain application is proposed, which can improve the transaction process of an office building.

Originality/value - Recent studies indicate that blockchain technology could lead to improvements in efficiency, transparency and therefore trust within the transaction process. Therefore, the proposed application is of value for the future of real estate data management and the transaction process.
\end{abstract}

Keywords Innovation, Commercial real estate, Blockchain technology, Transaction process, Information system, Design science research

Paper type Research paper

\section{Introduction}

Technology advances are transforming sectors across the globe, including the commercial real estate (CRE) sector. Parties acting in the CRE sector are evaluating their processes and institutions like banks, acting as trusted third party, are evaluating how to position in the future (Deloitte, 2017, 2018). The potential of technologies, such as artificial intelligence, big data and blockchain, is not only to streamline existing markets, but also to redistribute markets and create new ones (The Goldman Sachs Group, 2016).

Real estate is a unique, complex and the largest asset class in the world. History shows that real estate plays an important role in economies worldwide, is known to resist change, and seemingly allergic in adopting new technology (Spielman, 2016). The importance of real estate

\footnotetext{
(C) Hugo Pieter Wouda and Raymond Opdenakker. Published by Emerald Publishing Limited. This article is published under the Creative Commons Attribution (CC BY 4.0) licence. Anyone may reproduce, distribute, translate and create derivative works of this article (for both commercial \& non-commercial purposes), subject to full attribution to the original publication and authors. The full terms of this licence may be seen at http://creativecommons.org/licences/by/4.0/legalcode
}

Journal of Property Investment \& Finance

Vol. 37 No. 6, 2019 pp. $570-579$

Emerald Publishing Limited 1463-578X

DOI 10.1108/JPIF-06-2019-0085 
lies in the fact that it has been one of the three major asset classes that insurance companies and pension funds like to invest in - either directly, through property funds or Real Estate Investment Trusts or indirectly, through Mortgage-Backed securities or whole mortgages (Baum, 2017). Currently, real estate has become the largest asset class of the global stock market next to equities and bonds. However, real estate assets are distinctly different compared to equities and bonds by having high transaction costs, long-term commitment, regulations and other barriers to entry (Dijkstra, 2017). This is further supported by the markets' fundamental characteristics - heterogeneity and immobility. Hence, real estate transactions face the joint challenges of information inefficiencies and corresponding high transaction costs (Ling and Archer, 2002). Noteworthy, from a banks perspective, financing CRE is usually 60-70 percent loan-to-value, done through lending from banks (Gout, 2017). Due to technology advancements, changing client demand and stricter regulation (e.g. Basel III and Basel IV), the traditional role of banks is under pressure. In this context, for banks to stay relevant, current processes should be evaluated and business model "enablers" be researched.

Over the past few years, blockchain technology has raised interest all over the world. Blockchain technology originated from the whitepaper: Bitcoin: A Peer-to-Peer (P2P) Electronic Cash System, that was published in 2008 under the pseudonym Satoshi Nakamoto (2008). Blockchain is based on distributed ledger technology (DLT) (shared database). In simple terms, "a blockchain is a type of database that is replicated over a P2P network" (Hileman and Rauchs, 2017, p. 13). However, the definition of Hileman and Rauchs (2017) could be applied to other types of distributed databases as well. Subsequently, Dijkstra (2017) and Veuger (2017) examined the theoretically applicability of blockchain technology in the real estate management and real estate transaction process in general. Both studies indicate that blockchain technology could lead to improvements in efficiency, transparency and therefore trust. Additionally, banks could use blockchain to better understand the risks associated with real estate (Dijkstra, 2017). Although recent studies have examined the possibilities of applying blockchain technology, the specifics and applications remain unclear.

The combination of the cumbersome transaction process and the potentials of blockchain technology in the real estate sector forms the basis of this paper. Therefore, the aim of this paper is to propose an infrastructure for a blockchain-based application to enhance the current way real estate is transacted by introducing a more comprehensive, better quality and more complete asset information overview, which may payoff for all involved parties and might be an "enabler" for new business models. This sees two specific research questions concerning the improvement of the current transaction process as the empirical focus of the study:

$R Q 1$. How to implement blockchain technology to improve a real estate transaction of an office building?

$R Q 2$. What could be the potential role of a bank in a blockchain-based transaction?

\section{Research approach}

Literature states that blockchain technology can be applied to real estate and could be a gamechanger in transacting real estate. The focus on a solution for a field problem - the cumbersome transaction process - is in line with design science research. Design science research is based on pragmatic research and aims to create an innovative "artifact" that will help solve real-world problems (Hevner and Chatterjee, 2010, p. 9). For this reason, it is highly relevant to information system research. Hence, this method is applied in developing a design proposition for a field problem. The paper starts with a systematic review of previous work on real estate transactions and blockchain technology. However, no design concepts are found - as existing work is not established or developed enough - to provide greater conceptual clarity about a specific topic or field of evidence. Therefore, the synthesis focuses on scoping the research by the identification of major pain points within the current transaction process. Pain points have been identified 
JPIF

37,6

through semi-structured interviews with five experts involved in the process and then analyzed based on the Grounded Theory methodology. The findings of these interviews are used to develop a centralized infrastructure (without the use of blockchain) which overcomes the aforementioned pain points. Subsequently, blockchain technology can be introduced and compared to both the current method of data management (decentralized) and a centralized way of working. After designing the infrastructure of the blockchain model and user interface, the interviewees are asked again to pragmatically validate the proposed model. Using this method, it can be demonstrated that the developed blockchain model is promising and satisfies the expectations of future users.

\section{Background}

Commercial real estate transaction process

$\mathrm{CRE}$ - offices, industrial and logistics and residential real estate - is defined as tangible income producing assets of land and buildings but refers to title of ownership ("bundle" of "rights") as well (Geltner and Miller, 2001; Ling and Archer, 2002). In this research CRE is scoped to existing office buildings in the Netherlands. Due to the markets' fundamental characteristics heterogeneity and immobility - real estate transactions face the joint challenges of information inefficiencies and corresponding high transaction costs (Ling and Archer, 2002). Transactions in CRE take place in the asset market, which is part of the larger capital market. This market is divided into four categories (Geltner and Miller, 2001; Seuren, 2018): public equity market, private equity markets, public debt market and private debt market. This research focuses on (existing) office building transactions in the Dutch private equity market. The current transaction process of an office building can be divided into several stages (Crosby and McAllister, 2015; Dijkstra, 2017; Hordijk and Teuben, 2018; Just and Stapenhorst, 2018):

- preparation;

- marketing and pre-due diligence;

- due diligence; and

- completion.

During these stages multiple parties are involved and information relating to the property is shared. Currently, during the preparation phase all property-related information is gathered by the seller to present the office building in its best light. What is striking, is that owners increasingly analyze their own property-related information, which is called owners due diligence. Due to the decentralized way of working, information is stored in different formats and often on the servers of more than one party. Consequently, the real estate transaction process is known for its information-related issues. Throughout the transaction process, information is analyzed, and risk assessments are carried out by external advisors for the purchaser, called due diligence. Based on the analysis, a sales and purchase agreement is drafted and negotiated during the completion phase. Currently, due diligence phases and negotiations are carried out to verify and validate information. These processes are a key indicator of the lack of transparency and perceived unreliability of the data used in the transaction process. Furthermore, the decentralized way of working with various "nondigitized" documents makes the process complex and unstructured. Implementing new technologies could lead to an improvement in the transaction of an office building in the future.

\section{Blockchain technology}

Over the past few years, blockchain technology has raised interest all over the world - mainly as the underlying technology of "Bitcoin" (Blockchain 1.0) (Nakamoto, 2008; Swan, 2015). A blockchain distributed ledger is simply a new way of managing data and 
consists of five core elements (Hileman and Rauchs, 2017; Seuren, 2018; Tapscott and Tapscott, 2016; Tasca et al., 2017):

(1) DLT;

(2) peer-to-peer $(\mathrm{P} 2 \mathrm{P})$ network;

(3) cryptography;

(4) consensus mechanism; and

(5) validity rules.

Blockchain technology relies on DLT - a shared ledger between all participants (nodes) in the network. In this network P2P transactions - without the need of validation by a trusted third party - could be made between two or more nodes. Transactions in this P2P network are validated according to standards of a specific consensus mechanism. A consensus mechanism is an authorization method that allows some nodes to create new blocks after a set of predetermined validity rules is reached - validation of transactions. For example, the Proof of Authority mechanism enables nodes to use their "authorization" rules to create new blocks in a secured way (Hileman and Rauchs, 2017). To reach consensus, participants in a network must be able to trust each other. Within a blockchain network trust is created by cryptographic proof. Once the transaction is verified. The transaction is combined with other transactions and added to the chain of blocks, which is called a "hash." If a block is validated and hashed the data within the block is immutable. The transaction in the blockchain is completed.

Blockchain and its deriving applications, e.g. smart contracts (Blockchain 2.0) and realworld applications (Blockchain 3.0), could support and enhance the reliability, efficiency and security of data transferred among a network (Swan, 2015, p. ix). Therefore, blockchain technology features seem to provide a solution that could enhance the transaction process of office buildings. Although early studies of Dijkstra (2017), Spielman (2016), Seuren (2018) and Veuger (2017) indicated that blockchain technology is theoretically applicable in the real estate sector, limited research has focused on the development of applications and so how to implement the technology remains unclear. Therefore, it is interesting to do a more in-depth review of how the development of a blockchain application could improve the current transaction process.

\section{Implications for transacting real estate}

Earlier it is identified that real estate transactions are known for their lack of transparency, inefficiency and complexity. To support this, empirical findings identify and map pain points to specific phases and tasks in the transaction process. Grounded on the current transaction process, interviewees were asked: "What major pain points do you encounter during this process?" The interviewees spoke about how pain points mainly occur during the due diligence and completion phases leading to delays which result in a raise of (transaction) costs. However, pain points occur specifically during the preparation phase in the transaction process and the management of the real estate once the property has been acquired. Most problems are related to data structure and data quality. This makes sense as problems tend to arise when data are analyzed (manipulated and changed). If we are to improve the transaction process, the proposed solution should resolve identified pain points and, as a result, streamline the transaction process of an office building.

\section{Blockchain model}

In summary, organizations work in a decentralized fashion which causes various pain points and challenges. Although working in a centralized way is helpful to overcome
Blockchain technology 
JPIF 37,6

Figure 1.

Class diagram physical element the pain points, challenges such as reliability, transparency and security of data arise. In contrast, blockchain is simply a new method of decentralized structuring and handling data - which is often suitable but not often necessary. However, data management and hence streamlining transactions and data by implementing blockchain technology could be helpful to overcome the pain points and challenges. The proposed model is structured according to the data requirements of a transaction, which are split into two core elements:

(1) physical elements - technical related (Figure 1); and

(2) contractual elements - commercial, legal and financial documents.

Physical- and contractual-related data could be logged on the blockchain, based on its consensus mechanism and cryptographic encrypting method, also referred to as cryptographic audit trail or hash chain. The original files are stored on the servers of the involved parties and essential validation information is uploaded in the blockchain. The validated framework (Figure 1) consists of all essential data elements of a file (index code, validation date, signatures, etc.). The proposed audit trail keeps track of, in a log file, the adjustments that are made toward the "original" file. Validated record-keeping is the first step toward creating digital real estate transactions and resolving the pain points in the process.

To illustrate the proposed blockchain solution the infrastructure is visualized in Figure 2. The enhancement of the transaction process of an office building starts with the structure and quality of available information.

Although blockchain technology is what builds digital records of physical and contractual information, it does also come with challenges. These are a result of the immaturity of the technology, a lack of standardization and limited examples of successful application. Hence the implementation of the proposed model is quite complex. For the system to add value, data, such as reports, and inspection frameworks must be standardized. If this is possible, the record-keeping application could be linked to external databases (sources) by way of an application programming interface (API). Therefore, data could be automatically validated

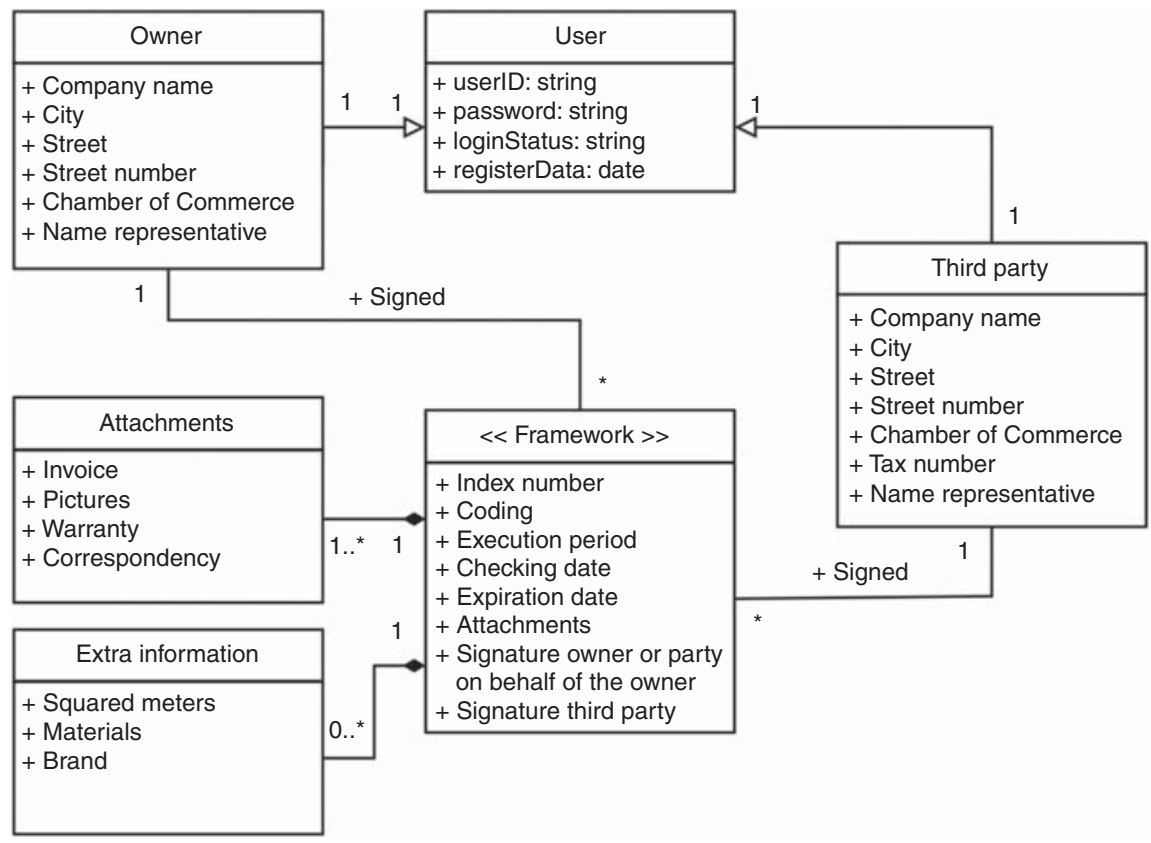




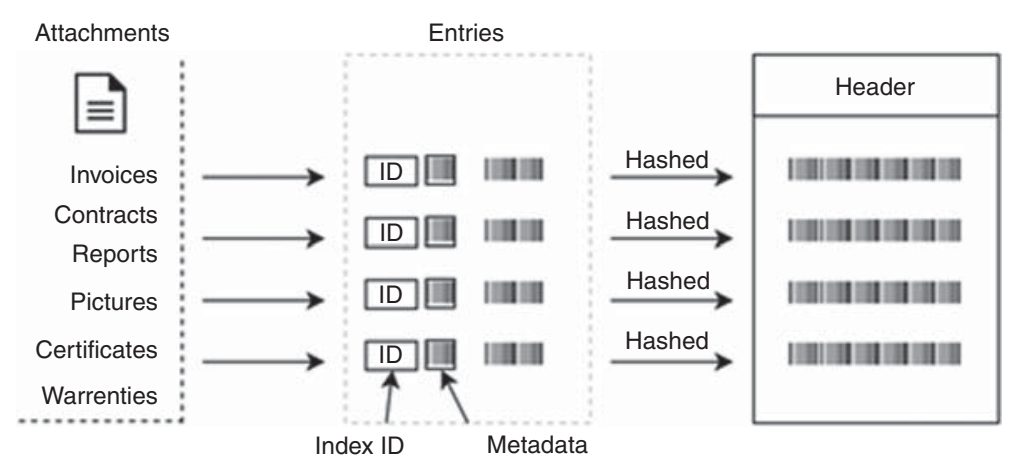

Blockchain technology

575

Figure 2.

Blockchain hash infrastructure

without the need for validating nodes and analyzed by the user. Also, authorization rules in the network could be much more written in detail (e.g. data such as contract clauses could be recorded). All this could make the proposed application suitable for managing physical and contractual data, which, consequentially, could enhance the transaction process.

\section{Validation}

For the blockchain model to be deemed acceptable, this research makes use of pragmatic validation to ensure that the model resolves the identified pain points. Dresch et al. (2015) stated that "the premise of design science is that the research conducted under its paradigm, in addition to being rigorous and scientifically valid, should also seek pragmatic validity, i.e., utility. In this context, pragmatic validity seeks to ensure that the solution proposed to solve a particular research problem will, in fact, work, which will ensure the achievement of the expected results" (p. 57). Therefore, the interviewees are asked again to validate the proposed model. Successful implementation of the proposed tool depends not only on the benefits that may be achieved for a bank, but for other involved parties in the network as well. Earlier we spoke about how the proposed blockchain model is a helpful tool to improve the current transaction process through greater security, transparency, reliability and efficiency. A property manager, for example, sees the added value of the tool to be in storing and sharing validated data without the need to interact with other parties. Other interviewees indicated that they would benefit from the increased transparency and therefore reliability in the process.

In line with the pragmatic validation, the role of banks in office building transactions was discussed extensively. Although the process is sector wide known to be cumbersome with problems related to unstructured-, non-digital-, unstandardized data which results in lacking data quality, there is not a great enough incentive for one single party to develop a blockchain infrastructure - all parties would have to sign up to use it for being valuable. The proposed blockchain infrastructure improves the cumbersome transaction process where banks can benefit from. Benefits for a bank - assuming that documents are standardized - are:

- More reliability: information in the network is validated by all parties and satisfies requirements. Based on this audit trail reliable reports can be generated, such as financing reports.

- Transparency: information shared between parties is the same.

- Efficiency: structured and standardized data can form the input for internal workflows and analyses, such as risk assessments. 
JPIF

37,6

Besides above-mentioned benefits social benefits occur as well. If the reliability and transparency of information enhances, fraud in real estate financing will be reduced. In addition, it is plausible that new ways of financing real estate can be developed based on the proposed infrastructure. Besides, all corporate parties could benefit from more reliability, transparency and efficiency as well. Hence, a collaboration between banks with a large market coverage would be best placed to take the lead in standardizing documents for financing real estate and, in turn, the development of a blockchain infrastructure as proposed. In this way, involved parties, such as banks, will receive standard information, which they can use to optimize their own internal workflows. When implementing the proposed infrastructure in combination with standardized contracts API's can be connected to various databases, whereby systems will be automated which speeds up the process of financing propositions and reduce associated risks.

\section{Results and discussion}

This research proposes a blockchain-based infrastructure to enhance the current transaction process of an office building. During validation of the application, all parties indicated that the application is an interesting first step toward a digital and more transparent ecosystem. The structure and quality of data - these are the main elements in a real estate transaction and so are essential if the process is to be streamlined - available will be enhanced by implementing the proposed blockchain infrastructure.

Currently, the proposed infrastructure enhances the transaction process due to its ability to structure data and guarantee quality by its encrypting and consensus methods. Although the transaction process of an office building almost look like the same compared to the "current" situation, reliability between parties and security within the network will be enhanced. As stated before, it would appear to the requesting party that a file is local while in fact it would be pulled from the blockchain and cached locally when needed. Figure 3 visualizes the proposed transaction process. Although all elements are almost the same as in the current process it could be assumed that the due diligence and negotiation process will be reduced in time by the implementation of this database, due to the enhancement of trust between involved parties and reliability of information. Hence, the proposed solution enhances the current transaction process.

Although from a technical perspective the model is interesting for future data management, there are challenges in how to implement the model. One of the interviewees said that no matter how much we rely on the digital world today, human input will still be essential. Therefore, the willingness to engage with the technology should be investigated. Furthermore, current real estate data are not created or held in a standard format and everyone interviewed spoke about the enormous challenge faced by data standardization. However, the proposed infrastructure is seen as interesting and promising development toward a more transparent process (based on structured and validated data) and a digital ecosystem.

In addition, new concepts such as "blockchain tokens" will be introduced to the real estate sector. Blockchain tokens are a digital representation of the economic value and ownership of property, by which they can be traded. However, one of the pain points identified is that it is difficult to define the characteristics of a property, due to lack of data structure and quality. This research proposes that the first step toward a digital representation of a building is to record the physical and contractual information. Hence, data in the blockchain database can serve as the foundation of a blockchain token, such as a validated annual report of a company.

Alongside the benefits of the proposed system, there are some challenges and one of the most important will be standardization. The added value of the system depends on it, but currently, the application could only be used to store and share "original" files. If documents (e.g. contracts, inspection reports, etc.) are standardized, then the validation of information could be automated by developing frameworks and connecting API's. One could imagine 


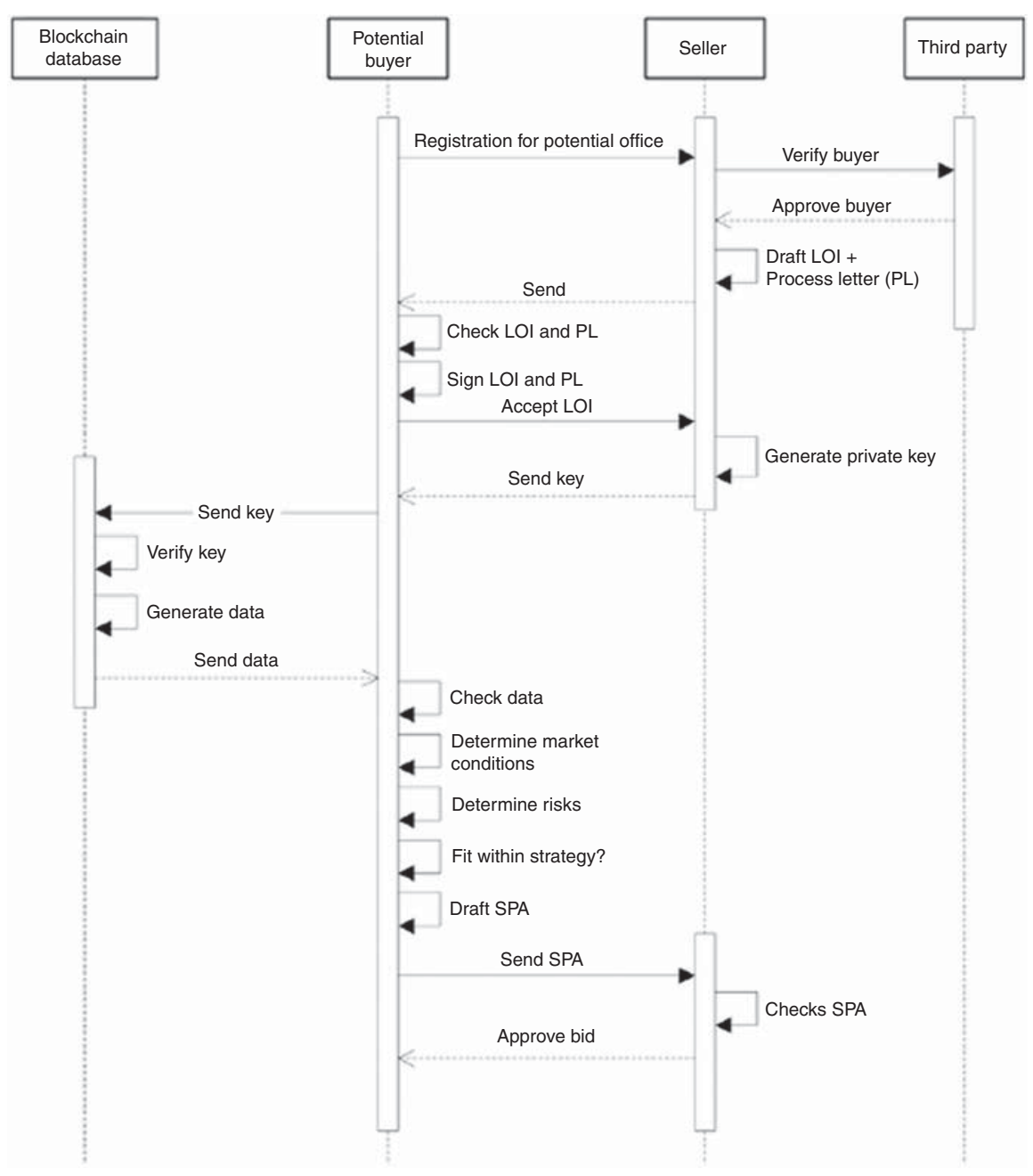

Blockchain technology

that the implementation of the proposed application could be phased, starting with the standardization of one or two indexes, such as lease contracts or inspection reports. Lease contracts would be beneficial as they are an important means of determining the economic value of the property and are based on a fundamental document, called the ROZ-model. Therefore, standardization of lease contracts could be an easy and valuable starting point.

All in all, the proposed application improves the way specific asset are understood by structuring physical and contractual information in one place and guarantees the quality of the data by using the blockchain mechanisms. Therefore, the tool is of value for the future of real estate data management and the transaction process.

\section{Limitations}

Although this research proposes an infrastructure for a blockchain application which can enhance the current process, this study has limited department, whereby various limitations 
JPIF

37,6 and subjects for further research can be identified. The limitations of this research are inherent to the scope of this research, the Dutch real estate market.

One limitation is that there was chosen to interview advisors within the real estate transaction process. Advisors are interviewed due to the involvement in various transaction processes, acting on behalf of the owner and their broad knowledge. Hence, a selective group of stakeholders in the transaction process is interviewed, which result in low external validity. To improve the external validity, more stakeholders could be interviewed to ensure that all roles are covered. Furthermore, a focus could be placed toward investors - the essential stakeholders in a transaction process.

In addition, research regarding legal- and technical topics are excluded from this research. For example, there are important European changes in data privacy regulation, called General Data Protection Regulation. Currently, research regarding the effect of privacy regulation on the proposed application still remains. The same applies toward the costs of the development and implementation of the proposed tool. When drawing the balance between the current situation and a blockchain database, further research toward these topics is needed.

As with all new technologies, such as blockchain technology, most research focus on the applicability, limited research focuses on the development of an application. Although this is not the first academic research that connects blockchain technology to real estate transactions, it is the first research that proposes a blockchain technology-based application. However, due to the limited practical use cases, this research came up with various assumptions (e.g. technical and legal) how blockchain should be implemented. Hence, further research toward these assumptions is needed.

\section{References}

Baum, A. (2017), "PropTech 3.0: the future of real estate", report, Saïd Business School, University of Oxford, Oxford.

Crosby, N. and McAllister, P. (2015), "Liquidity in commercial property markets: deconstructing the transaction process", University of Reading Business School, Reading.

Deloitte (2017), "Blockchain in commercial real estate: the future is here!", Deloitte Center for Financial Services.

Deloitte (2018), "Building the future: real estate predictions 2018”, Deloitte, Amsterdam.

Dijkstra, M. (2017), "Blockchain: towards disruption in the real estate sector", Delft University of Technology, Delft.

Dresch, A., Lacerda, D. and Antunes, J. Jr (2015), Design Science Research: A Method for Science and Technology Advancement, Springer International Publishing, London.

Geltner, D. and Miller, N. (2001), Commercial Real Estate Analysis and Investments, Cengage Learning, Cincinnati, $\mathrm{OH}$.

Gout, B. (2017), "Block and mortar: a blockchain-inspired business model for a mortgage funding marketplace", Delft University of Technology, Delft.

Hevner, A. and Chatterjee, S. (2010), "Design science in information systems research", in Hevner, A. and Chatterjee, S. (Eds), Design Science Research in Information Systems, Springer, New York, NY, pp. 9-12.

Hileman, G. and Rauchs, M. (2017), "Global blockchain benchmarking study”, Cambridge Centre for Alternative Finance, Cambridge.

Hordijk, A. and Teuben, B. (2018), "The liquidity of direct real estate in institutional investors portfolios: the Netherlands", Journal of Property Investment \& Finance, Vol. 1 No. 26, pp. 38-58.

Just, T. and Stapenhorst, H. (2018), Real Estate Due Diligence: A Guideline for Practitioners, Springer International Publishing, Cham. 
Ling, D. and Archer, W. (2002), "The nature of real estate and real estate markets", in Ling, D. and Archer, W. (Eds), Real Estate Principles: A Value Approach, McGraw-Hill, New York, NY, pp. 1-17.

Nakamoto, S. (2008), Bitcoin: A Peer-to-Peer Electronic Cash System.

Seuren, F. (2018), "Introducing blockchain to commercial real estate", Delft University of Technology, Delft.

Spielman, A. (2016), "Blockchain: digitally rebuilding the real estate industry", doctoral dissertation, Massachusetts Institute of Technology.

Swan, M. (2015), Blockchain: Blueprint for a New Economy, O’Reilly Media, Sebastopol, CA.

Tapscott, D. and Tapscott, A. (2016), Blockchain Revolution: How the Technology behind Bitcoin and Other Cryptocurrencies is CHANGING the World, Penguin, London.

Tasca, P., Thanabalasingham, T. and Tessone, C. (2017), "Ontology of blockchain technologies: principles of identification and classification", University College of London, London.

The Goldman Sachs Group (2016), Profiles in Innovation: Blockchain Putting Theory into Practice, The Goldman Sachs Group.

Veuger, J. (2017), Een Wendbare Vastgoedeconomie met Disruptie \& Blockchain, Hanzehogeschool Groningen: Univerity of Applied Sciences, Groningen.

\section{Corresponding author}

Raymond Opdenakker can be contacted at: r.j.g.opdenakker@tue.nl

For instructions on how to order reprints of this article, please visit our website: 